\title{
Yawn contagion in humans and bonobos: emotional affinity more than species matters
}

[p] In humans

and apes, yawn contagion echoes emotional contagion, the basal layer of empathy. Hence, yawn contagion is a unique tool to compare empathy across species. If humans are the most empathic animal species, they should show the highest empathic response also at the level of emotional contagion. We gathered data on yawn contagion in humans (Homo sapiens) and bonobos (Pan paniscus) by applying the same observational paradigm and identical operational definitions. We selected a naturalistic approach because experimental management practices can produce different psychological and behavioural biases in the two species, and differential attention to artificial stimuli. Within species, yawn contagion was highest between strongly bonded subjects. Between species, sensitivity to others' yawns was higher in humans than in bonobos when involving kin and friends but was similar when considering weakly-bonded subjects. Thus, emotional contagion is not always highest in humans. The cognitive components concur in awakening and nourishing emotional affinity between individuals. Yet, when they are not in play, humans climb down from the empathic podium to return to the "understory", which our species shares with apes. [p] 
1 YAWN CONTAGION IN HUMANS AND BONOBOS: EMOTIONAL AFFINITY MORE

2 THAN SPECIES MATTERS

3

4 ELISABETTA PALAGI ${ }^{1,2}$, IVAN NORSCIA $^{1}$ and ELISA DEMURU ${ }^{1,3}$

$5 \quad$ Natural History Museum, University of Pisa, Via Roma 79, 56011, Calci, Pisa, Italy

$6{ }^{2}$ Institute of Cognitive Sciences and Technologies, Unit of Cognitive Primatology \& Primate

7 Center, CNR, Via Aldrovandi 2, 00197, Rome

$8{ }^{3}$ Bioscience Department, University of Parma, Parco Area delle Scienze, 11/A, 43124, Parma 


\section{ABSTRACT}

10 In humans and apes, yawn contagion echoes emotional contagion, the basal layer of empathy.

11 Hence, yawn contagion is a unique tool to compare empathy across species. If humans are the

12 most empathic animal species, they should show the highest empathic response also at the level

13 of emotional contagion. We gathered data on yawn contagion in humans (Homo sapiens) and

14 bonobos (Pan paniscus) by applying the same observational paradigm and identical operational

15 definitions. We selected a naturalistic approach because experimental management practices can

16 produce different psychological and behavioural biases in the two species, and differential

17 attention to artificial stimuli. Within species, yawn contagion was highest between strongly

18 bonded subjects. Between species, sensitivity to others' yawns was higher in humans than in

19 bonobos when involving kin and friends but was similar when considering weakly-bonded

20 subjects. Thus, emotional contagion is not always highest in humans. The cognitive components

21 concur in awakening and nourishing emotional affinity between individuals. Yet, when they are

22 not in play, humans climb down from the empathic podium to return to the "understory", which

23 our species shares with apes.

25 KEYWORDS: Homo sapiens; Pan paniscus; emotional contagion; affective empathy; cognitive

26 empathy; cross-species comparison 
INTRODUCTION

28 Most behavioral and cognitive studies have used the most sophisticated human abilities (e.g.

29 theory of mind and language) as the main ground to make comparative arguments. Yet, this top-

30 down approach has contributed to drawing the line between human and other animals' skills.

31 Indeed, selecting the emotional and cognitive pinnacles of the human brain (sensu de Waal \&

32 Ferrari, 2010) can shed light on unique human traits but not on the common basic mechanisms

33 underlying the more complex ones (de Waal \& Ferrari, 2010; Hecht et al., 2012). While the

34 hominin fossil record cannot give us any clues on the social and emotional abilities that may have

35 paved the way for the emergence of human empathy, studying synchronous behaviours and body

36 resonance (e.g. laughing, rapid facial mimicry, yawning; Provine, 2012; Davila-Ross et al., 2008;

37 Mancini et al., 2013a) in our closest living relatives may provide valuable information about how

38 empathy evolved.

39 Empathy is a multilayered phenomenon, whose shared basal forms represent the pre-existing

40 framework in which more complex emotional and cognitive processes are nestled (Preston \& de

41 Waal, 2002; de Waal, 2008). Perceiving and sharing others' emotions, the so called

42 "affective empathy", is a phylogenetically old capacity. Affective empathy is

43 an automatic process and may come about through emotional contagion (de

44 Waal, 2008). At a higher layer of the empathic sphere, we find "cognitive

45 empathy" which requires self-other differentiation, perspective-taking and

46 mental state attribution, basic capacities to infer others' emotional states.

47 Affective and cognitive empathy dissociate in humans with the former

48 preceding the latter both ontogenetically and phylogenetically (Decety,

49 2010). Humans show the most complex form of empathy and, therefore, are commonly deemed

50 as the most empathic species (Preston \& de Waal, 2002; Decety, 2004; Decety \& Cowell, 2014). 
51 However, no quantitative, direct inter-specific comparison has ever been made to actually

52 demonstrate that this assumption is true at each floor of the empathic building. Recent findings

53 endorse that other animals show affective empathy (Palagi et al., 2009; de Waal, 2012a; Panksepp

$54 \&$ Panksepp, 2013). In this view, cross-species research is needed to explore empathy capacities

55 as a bottom-up, emotional and developmental process of the brain (de Waal, 2012b). According

56 to several neurobiological (Cooper et al., 2012; Haker et al., 2013), psychological (Lehmann,

57 1979; Platek et al., 2003) and ethological findings (Palagi et al., 2009; Campbell \& de Waal,

58 2011, 2014; Romero et al., 2013) yawn contagion is an empathy-related phenomenon.

59 Specifically, yawn contagion is a form of emotional contagion, which represents the most basal

60 layer of the empathic sphere (Preston \& de Waal, 2002; Hatfield et al., 2009). Several good

61 reasons make the yawn and its contagion excellent phenomena to explore the evolutionary roots

62 of empathy.

63 Due to its evolutionary antiquity, a yawn can be easily detected and quantified, appearing

64 morphologically identical across many different vertebrate taxa and, consequently, withdrawing

65 the risk of any subjective interpretation (Provine, 2005). Therefore, the plesiomorphic nature of

66 yawning enables cross-species research (Baenninger 1987, 1997; Deputte, 1994; Guggisberg et

67 al., 2010). Yawning is automatic, unstoppable and easily recognisable also when people try to

68 hide or inhibit it due to cultural constraints (Lehmann, 1979). These features make this behaviour

69 an honest signal and, therefore, highly reliable (Provine, 1986).

70 Yawn contagion is obvious in human beings - about 50 percent respond to video stimuli of

71 yawning faces (Provine, 1986) - and seems to be based on a perception-action mechanism

72 (Preston \& de Waal, 2002; de Waal, 2012c), which consists in the involuntary re-enactment of an

73 observed facial expression and creates shared representations. Neurophysiological evidence of

74 this coupling has derived from the discovery of mirror neurons (di Pellegrino et al., 1992),

75 recently associated with yawn contagion (Cooper et al., 2012; Haker et al., 2013). Therefore, 
76 yawn contagion provides a "low-tech" but significant evidence of mirror-like phenomena. Mirror

77 neurons, firstly described in the pre-frontal cortex of the rhesus macaque, fires when the subject

78 either performs a motor action or observes the same action performed by another subject (Gallese

79 et al., 1996; Ferrari et al., 2003). A mirror system, homologous to that of macaques, has been later

80 discovered in humans (Rizzolatti \& Craighero, 2004). The mirror mechanism (or motor

81 mimicry), not requiring any kind of conscious awareness, creates an emotional bridge and, thanks

82 to it, two individuals can synchronize their affective states (Hatfield et al., 2009). This emotional

83 bridge, in turn, fosters mirroring and triggers a positive feedback which constitutes the core of

84 social affinity. Such feedback is more easily activated when subjects sharing a strong empathic

85 bonding are involved. While a positive attachment enhances body and emotional resonance (e.g.

86 emotional reactions, unconscious mimicry, self-other overlap and shared representations), a

87 negative attachment or a prejudice can inhibit or suppress it (Xu et al., 2009; Avenanti et al.,

88 2010). In humans, when the attachment is profoundly negative (as in case of defectors, enemies,

89 competitors) empathy can even turn into Schadenfreude that is feeling pleasure from the

90 sufferings of others (de Waal, 2008; Decety \& Cowell, 2014). This emotional circuitry, in its

91 positive and negative form, has been found not only in humans (Singer et al., 2006; Pfeifer et al.,

92 2008) but also in monkeys (Masserman et al., 1964; Palagi et al., 2009; Mancini et al., 2013a,b;

93 Ferrari et al., 2009; Paukner et al., 2009) and apes (Anderson et al., 2004; Davila-Ross et al.,

94 2008; Campbell \& de Waal, 2011, 2014).

95 In humans (Homo sapiens) and one of its closest living phylogenetic relatives, the bonobo (Pan

96 paniscus), yawn contagion is present and significantly affected by the emotional closeness

97 linking the responder to the first yawner (the trigger). In the two species, the yawn response is

98 most likely when the yawning stimulus comes from kin or friends (Norscia \& Palagi, 2011;

99 Demuru \& Palagi, 2012). Since both in humans and bonobos yawn contagion is a socially

100 modulated phenomenon, these species are good models to test some hypotheses on the 
101 evolutionary origins of the linkage between yawn contagion and empathy. The opportunity

102 provided by yawn contagion to apply the same unit of measurement and identical operational

103 definitions permits to directly compare human empathy with that of other species. Indeed, most

104 of the studies on empathic capacities in Homo sapiens have been carried out through

105 questionnaires used to measure self-reported scores of empathy. This approach bears the risk of

106 overestimating the human empathic potential and leads to the unfeasibility of comparing it to that

107 of other species (Lawrence et al., 2004).

108 As a whole, the possibility to employ a highly straightforward behaviour, such as yawning, to

109 explore a highly complex phenomenon, such as empathy, represents a unique opportunity to

110 investigate and compare empathy in human and non-human species (de Waal, 2012b).

111 Theoretically, humans could appear as the most empathic species not because they experience

112 greater emotional contagion (affective empathy) but because they can better understand others'

113 perspective and simulate others' emotional experiences (cognitive empathy). Indeed, empathy is a

114 construct comprising dissociable components interacting and operating in parallel (Decety \&

115 Cowell, 2014). Cognitive empathy can be impaired in autistic subjects (Dziobek et al., 2008;

116 Usui et al., 2013) whereas emotional empathy can be dramatically impaired in narcissistic

117 individuals (Ritter et al. 2011), criminal psychopaths (Woodworth \& Porter, 2002), rapists

118 (Englander, 2007), and child molesters (Marshall et al., 2001). Yet, both emotional and cognitive

119 empathy contribute to physiological human empathy (Cox et al., 2011; Decety \& Cowell, 2014).

120 Therefore, if humans are actually the most empathic species, they should possess the highest

121 empathic response starting with emotional contagion, the ground level of affective empathy.

122 We tested this hypothesis by comparing our species with bonobos, which diverged from the

123 human line about 5-7 mya (Fleagle, 2013). We expect that the frequency of yawn response is

124 always higher in humans than in bonobos, whatever the relationship quality linking the responder

125 to the trigger. Since the time elapsing from the yawn stimulus to the response can be reduced 
126 when the social bond is strong (Norscia \& Palagi, 2011), we also expect that the emotional

127 affinity linking the subjects affects, more in humans than in bonobos, the promptness of the yawn 128 response.

\section{METHODS}

\section{1 (a) Ethics statement}

132 This study was purely observational, with no manipulation whatsoever. For humans, information 133 was entered in an anonymous form. Thus, the ethics committee of the University of Pisa waived 134 the need for a permit.

\section{5 (b) Data collection}

136 We gathered data on yawn contagion in both species in their daily life environment, by applying

137 the same observational paradigm based on identical operational definitions. The naturalistic 138 approach has been selected because it permits to collect reliable data thanks to the absence of 139 invasive, artificial management practices (social isolation, spatial limitation, interaction with 140 novel objects and persons) which can produce different psychological and behavioural biases in

141 the two species, and differential attention to artificial stimuli. For example, previous research on 142 humans has demonstrated that the awareness of being observed can inhibit yawns (Provine, 2005)

143 whereas simply reading about yawning is sufficient to trigger yawns (Provine, 1986) and possibly

144 inflate yawn response in the experimental subjects (Bartholomew \& Cirulli, 2014).

145 Humans - Naturalistic observations on humans were performed over a total of 380 hours (in 1462010,2011 and 2013) and involved 33 adults, 19 females and 14 males. The study subjects were 147 observed during their everyday activity, in their natural social setting (at work, in restaurants, 148 waiting rooms, during social meals, etc.). In public spaces, the authors sat down close to the study 149 subjects and observed. Subjects included people known to the authors, such as friends, family 150 members, coworkers, and students. The study also included individuals that the authors did not 
151 know but whose personal information (e.g., country of origin and social bond with other study

152 subjects) was stated by the observed subjects during conversations. Data were typed and stored in

153 mobile phones (e.g., during dinners), entered in the laptop (when possible, e.g., on the train), or

154 noted down on paper (e.g., in public spaces where this practice could easily go unnoticed). Data

155 collection occurred only when at least five subjects were present to make observations on humans

156 comparable with the observations on bonobos (see below). During each observation bout

157 (spanning 1-4 hours), yawns were collected via the all occurrences sampling method (Altmann,

158 1974). Dyads of strangers were excluded. We collected a total of 1375 yawn events. The

159 observed subjects were not aware of being under investigation and the data collected were

160 entered in an anonymous form with an alphanumerical code uniquely assigned to each subject.

161 Bonobos - Naturalistic observations on bonobos were daily performed on the colonies hosted at

162 the Apenhuel Primate Park (Apeldoorn, The Netherlands) and at the Wilhelma Zoo (Stuttgart,

163 Germany) for a total of 502 and 323 hours, respectively (2009/2010). The all occurrences

164 sampling observations involved 16 adults, 12 females and 4 males in different contexts (foraging,

165 resting, feeding both indoor and outdoor). At least five bonobos were always present in the same

166 enclosure. During each observation bout (spanning 2-5 hours), yawns were collected via the all

167 occurrences sampling (Altmann, 1974). We collected a total of 1125 yawn events for the

168 Apenheul group and 998 for the Stuttgart group.

169 Both for humans and bonobos when a subject spontaneously yawned, we recorded 1) time; 2) the 170 encoded identity of the yawner (hereafter, the "trigger") and of each potential responder

171 (hereafter, the "observer"), that is every individual that could visually and/or auditorily perceive

172 the triggering yawn; 3) presence/absence of contagion within 3-min following the last triggering

173 yawn; 4) time latency in the yawn response; 5) trigger's and observer's sex. Before starting

174 systematic data collection, the three observers (the authors) underwent a training period during

175 which they simultaneously followed the same group of subjects. The training procedures were 
176 identical for the two species. Each yawning event and the possibility to perceive it by other

177 observed subject were the items we considered for the calculation of the Cohen's kappa. Training

178 ended when the observations produced a Cohen's kappa $>0.80$. Every 50 hours of data collection

179 we checked observational reliability (Cohen’s kappa never $<0.80$ ).

180 (c) Operational definitions

181 In humans we defined strongly and weakly bonded dyads on the basis of previous literature

182 (Norscia \& Palagi, 2011). Friends, regular partners, and kin were labeled as strongly bonded

183 dyads. Friends were defined as non related individuals sharing a direct relationship, frequenting

184 each other voluntarily. Regular partners were defined as couples living together from at least one 185 year. Those dyads having a coefficient of relatedness $r \geq 0.25$ were defined as kin ( 7 dyads, $r=0.5$;

1861 dyad=0.25). Weakly bonded dyads involved acquaintances, that is people who exclusively 187 shared an indirect relationship based on a third external reference, for example work duty 188 (colleagues) or friends in common (friends of friends). The relationship between people was 189 known to the authors. Ambiguous cases were excluded from the dataset (e.g. kin with $\mathrm{r}<0.25$, 190 colleagues frequenting each other outside work).

191 In bonobos we also categorized strongly and weakly bonded dyads on the basis of previous 192 literature (Demuru \& Palagi, 2012; Palagi \& Norscia, 2013). By focal animal sampling (Altmann, 1931974 - 25 hours of observation per subject), we were able to record all the contact sitting, 194 grooming, and food sharing sessions performed by each focal animal with any other group 195 member. Each subject was followed every day (each focal lasted 30 minutes) and at different 196 times to obtain data covering the entire day in balanced proportions as much as possible. Friends 197 and kin were clustered into the strongly bonded category. Friend dyads were categorized using a 198 combined measure of the three behaviors collected during focal observations and calculating the 199 quartile points of dyadic scores for each focal individual. Only dyads with scores falling into the 200 top quartile were considered as friends. Kinship was based on maternal lineages only, as paternity 
201 was unknown. Our kin sample consisted in 7 dyads $(r=0.5)$, all showing top frequencies of

202 affinitive contact exchange (strong bond). All the dyads not included in the previous categories

203 (non-kin dyads' scores falling outside the top quartile) were labeled as weakly bonded.

\section{4 (d) Statistics}

205 Due to the normality of data (Kruskall-Wallis, $\mathrm{p}>0.05$ ), we made use of parametric statistics.

206 Independent sample t-test was used to compare the frequency and the latency of yawn contagion

207 between the two species.

208 To explore the effect of the different variables on the frequency of yawn contagion we analyzed

209 data via Linear Mixed Model (LMM). The dependent scale variable was the relative frequency of

210 yawn contagion of each observer; that is, the number of yawns the observer performed after

211 perceiving a given trigger's yawn normalized on the number of occasions (number of a given

212 trigger's yawns perceived by the observer). In the analysis, triggers and observers' identities were

213 entered as random factors (nominal variables). We tested models for each combination involving

214 the variables of interest, spanning from a single-variable model to a model including all the fixed

215 factors (full model). To select the best model, we used the Akaike's Corrected Information

216 Criterion (AICc), a measure for comparing mixed models based on the -2 (Restricted) log

217 likelihood. The AICc corrects the Akaike's Information Criterion (AIC) for small sample sizes.

218 As the sample size increases, the AICc converges to AIC. The model with a lower value of AIC

219 was considered to be the best model. To avoid the increase of type II errors, factors were

220 excluded from a model only if this improved the model fit by $>2$ AICc units. The value of

221 degrees of freedom is given by the effective sample size $(\mathrm{N})$ minus the rank design matrix of

222 fixed effects $(\mathrm{X})$. The denominator degree of freedom is estimated by SPSS via Satterthwaite's

223 approximation.

224 To check for the inter-specific differences in the frequency of yawn contagion between weakly 225 and strongly bonded dyads we applied the randomization test for two independent samples. This 
226 kind of procedure is used to avoid pseudo-replication due to non-independence of data (the same

227 individual is included in more than one dyad; therefore, dyads are not independent data-points).

228 Specifically, randomization tests were employed with a number of 10,000 permutations using

229 resampling procedures (via Resampling Procedures 1.3 package by David C. Howell).

230 To test for the individual differences in the latency of yawn contagion as a function of 231 relationship quality shared by subjects, we used the paired sample t-test.

233 RESULTS

234 The individual yawn response did not differ between the two species (mean yawn response $\pm \mathrm{SE}$ :

235 Homo $=0.296 \pm 0.042 ;$ Pan $=0.210 \pm 0.029$; Independent sample test: $\mathrm{t}=1.348 ; \mathrm{df}=47 ; \mathrm{p}=0.184)$.

236 Both humans (Norscia \& Palagi, 2011) and bonobos (Demuru \& Palagi, 2012) (Supplementary

237 Video 1) preferentially responded within the first minute after perceiving a yawn. However, our 238 direct comparison between the two species showed that, within the first minute, humans' 239 responses were more frequent than bonobos' (first minute: Independent sample test: $\mathrm{t}=3.854$; $240 \mathrm{df}=37 ; \mathrm{p}<0.0001$ ), who showed a longer tail-effect in their contagion response compared to 241 humans (second minute: $\mathrm{t}=-0.737 ; \mathrm{df}=37 ; \mathrm{p}=0.466$; third minute: $\mathrm{t}=-7.555 ; \mathrm{df}=37 ; \mathrm{p}<0.0001$ )

242 (Fig. 1). Since this analysis considered three different minutes in which yawn contagion may 243 occur, only the subjects showing at least three contagion events were included in the test.

244 We employed Linear Mixed Models (LMM) to verify which variables could explain the variation 245 in the frequency of yawn contagion (dependent variable). Data distribution was normal. Species 246 (Homo sapiens/Pan paniscus), trigger and observer's sex, and social bonding (weak/strong) were 247 entered as fixed factors. Trigger and observer's identities were entered as random factors. This 248 analysis was restricted to those dyads in which each contagion event could be univocally 249 assigned to a specific trigger and when the opportunities were at least 3 per dyad. For these 
reasons, the LMM dataset included 44 human and 56 bonobo dyads with 375 and 484 contagion

251 events, respectively.

252 Both species and social bonding remained in the best model (best model AICc $=-3.312$; worst 253 model $\left._{\text {intercept only }} \mathrm{AICc}=6.828\right)$ and significantly affected the frequency of yawn contagion (Table 254 1).

255 In both humans and bonobos, yawn contagion was higher between individuals sharing strong 256 relationships (randomization test for two independent samples: bonobos, $t=-2.772, \mathrm{~N}_{\text {strong }}=28$ 257 dyads, $\mathrm{N}_{\text {weak }}=28$ dyads $\mathrm{p}=0.0061$; humans, $\mathrm{t}=-3.646, \mathrm{~N}_{\text {strong }}=28$ dyads, $\mathrm{N}_{\text {weak }}=16$ dyads, $\mathrm{p}=0.0007$ ).

258 At the inter-specific level, the frequency of yawn contagion in humans and bonobos significantly 259 differed only when strongly bonded dyads $\left(\mathrm{N}_{\text {Pan }}=28 ; \mathrm{N}_{\text {Homo }}=28\right)$ were involved (randomization 260 test for two independent samples $\mathrm{t}=-3.916, \mathrm{p}=0.0001$ ). On the contrary, weakly bonded dyads $261\left(\mathrm{~N}_{\text {Pan }}=28 ; \mathrm{N}_{\text {Homo }}=16\right)$ of the two species did not differ in the frequency of yawn contagion 262 (randomization test for two independent samples $\mathrm{t}=-0.799, \mathrm{p}=0.455$ ) (Fig. 2).

263 In order to understand if the response latency was affected by the relationship quality shared by 264 the trigger and the responder in the two species, we analyzed the minute distribution of the 265 response as a function of weak and strong bonds. In bonobos, the analysis showed that the 266 response latency did not change as a function of the relationship quality (Paired sample test: $\mathrm{t}_{1 \mathrm{~min}}$ $267=-0.233, \mathrm{df}=12, \mathrm{p}=0.820 ; \mathrm{t}_{2 \min }=0.196, \mathrm{df}=12, \mathrm{p}=0.848 ; \mathrm{t}_{3 \min }=0.199, \mathrm{df}=12, \mathrm{p}=0.846 ;$ Fig. 3a). On 268 the contrary, in humans, the response latency was sensitive to the relationship quality. The human 269 subjects concentrated their response within the first minute only when the yawn stimulus came 270 from a strongly bonded subject (Paired sample test: $\mathrm{t}_{1 \min }=4.760, \mathrm{df}=12, \mathrm{p}=0.0001$ ). On the other 271 hand, the human subjects responded more frequently in the second and third minute after 272 perceiving the yawn stimulus from a weakly bonded trigger $\left(\mathrm{t}_{2 \min }=-3.774, \mathrm{df}=12, \mathrm{p}=0.003 ; \mathrm{t}_{3 \min }\right.$ $273=-2.670, \mathrm{df}=12, \mathrm{p}=0.020$; Fig. $3 \mathrm{~b}$ ). All these analyses included only subjects showing at least 274 three contagion response per each bonding category (weak and strong). 


\section{DISCUSSION}

277 The inter-specific analysis of the overall frequency of yawn contagion did not reveal any

278 difference between human and bonobo response susceptibility. The inter-species comparison

279 revealed a higher promptness in humans than in bonobos, who showed a longer tail-effect in their

280 response latency. However, both species concentrated their responses within the first minute after

281 perceiving the stimulus yawn (Figure 1). Being yawn contagion the expression of a mirror-like

282 phenomenon (Cooper et al., 2012; Haker et al., 2013), our findings suggest not only that yawn

283 contagion is well-rooted in the biology of bonobos and humans but also that the neural processes

284 underlying and modulating yawn contagion might have been already present in the most recent

285 common ancestor of the two species (5-7 mya, Fleagle, 2013). The similar sensitivity to others'

286 yawns shown by the two species is probably due to similar selective pressures. In fact, both

287 species are characterized by obligate gregariousness based on one of the most complex forms of

288 social structure: the fission-fusion system (Aureli et al., 2008). Behavioural (Couzin, 2007) and

289 emotional synchronization (Špinka, 2012) has been playing a pivotal role in favouring and

290 shaping the evolutionary pathways leading to social living (Supplementary Video 1).

291 Synchronizing with others requires the ability to mirror their motor actions, to experience their

292 emotional states and, consequently, to act in the appropriate manner. In this process familiarity

293 makes the difference. Our intra-specific analysis demonstrated that yawn contagion is a socially

294 modulated phenomenon, with strongly bonded subjects showing a higher susceptibility than

295 weakly bonded subjects, thus confirming previous results (humans, Norscia \& Palagi, 2011;

296 bonobos, Demuru \& Palagi, 2012). In this respect, the degree of contagion of around 50\%

297 reported by previous studies using videos of strangers' yawns as stimuli (Provine 2005) may be a

298 conservative estimate. 
299 The social modulation of yawn contagion has been proven also in the congeneric species of

300 bonobos, the chimpanzee (Pan troglodytes). Chimpanzees are more susceptible to respond to

301 videos showing yawns performed by in-group than by out-group members (Campbell \& de Waal,

302 2011). This result is in line with a great body of research on human in-group/out-group bias that

303 affects numerous empathy-driven behavioural and emotional reactions (Bourgeois \& Hess, 2008;

304 Xu et al., 2009; Avenanti et al., 2010). Recently, Campbell and de Waal (2014) also found that the

305 rate of chimpanzee response to others' yawns was similar when the stimulus came from an in-

306 group chimpanzee and from a human subject, thus demonstrating that the chimpanzee

307 involuntary empathic response goes beyond the species boundary, as it occurs in humans

308 (Phillips, 2009). Yet, no evidence of a social modulation in chimpanzee yawn contagion emerged

309 as a function of the relationship quality shared between the responder and the in-group, familiar

310 trigger (Massen et al., 2012). Both neuroanatomical (Rilling et al., 2012) and behavioral features

311 (Hare et al., 2012) can account for the different effect of the relationship quality on chimpanzee

312 and bonobo yawn contagion. Compared to chimpanzees, bonobos seem to show a different

313 emotional and affective sensitivity (Furuichi, 2011; de Waal \& Lanting, 1997; Hare et al., 2007)

314 and a milder competitive propensity (Kano, 1992; Tan \& Hare, 2013). Moreover, genetic findings

315 revealed that a DNA segment regulating the responses to a hormone involved in social bonding

316 (vasopressin) is present in humans and bonobos, but can lack in chimpanzees (Hammock \&

317 Young, 2005). However, the different effects of the relationship quality on yawn contagion in the

318 two Pan species has to be taken cautiously due to the different methodological approaches used

319 to verify and quantify the phenomenon (video stimulus - Massen et al., 2012; living stimulus -

320 Demuru \& Palagi, 2012).

321 At the inter-specific level, striking differences emerged in the social modulation of human and

322 bonobo yawn contagion. While strong and weak relationships between individuals had to be 323 assessed according to species-specific criteria (see Methods section), the previous works on 
324 bonobos (Demuru \& Palagi, 2012) and humans (Norscia \& Palagi, 2011) indicate that the strong-

325 weak categorization produces a similar effect on yawn contagion in either species, with yawn

326 contagion being highest between individuals sharing strong relationships. This result is confirmed

327 in this study. Compared to bonobos, the human susceptibility (Figure 2) and promptness (Figure

328 3) to others' yawns were significantly more potentiated when kin and friends were involved.

329 Humans' responses were more frequent and faster when the trigger and the responder shared a

330 strong emotional bond. On the other hand, susceptibility and promptness incredibly overlapped

331 between the two species when a strong emotional involvement between subjects was lacking,

332 thus indicating that emotional contagion is not always highest in humans. It is worth remarking

333 that these findings would have been impossible to detect if limiting the analysis to the intra-

334 specific level.

335 What explains the difference in yawn contagion between species is the deepness of the emotional

336 affinity linking the subjects. Compared to bonobos, humans show a different degree of

337 sensitiveness at the most basal layer of empathy, but only when they are strongly emotionally

338 involved. Moreover, the latency of yawn contagion is socially modulated in humans (the stronger

339 the emotional involvement, the faster the response) but not in bonobos. Therefore, the positive

340 feedback linking emotional affinity and the mirroring process is more easily and rapidly activated

341 in humans than in bonobos. Such over-activation explains not only the human potentiated

342 yawning response, but also other kinds of unconscious mimicry response, such as happy, pain or

343 angry facial expressions (Chiao et al., 2008). Minagawa-Kawai and coworkers (2009)

344 investigated the response latency of smiles in mother-infant pairs and found neurobiological

345 support for the "over-activation" hypothesis. The faster response was associated with an increased

346 activation in the regions around the orbitofrontal cortex in mothers while viewing their own

347 infant's smile compared to an unfamiliar infant's smile. In these mothers, specific neuronal

348 regions involved in positive emotional regulation were activated by both viewing familiar and 
349 unfamiliar infants but the magnitude of activation was greater when affective attachment was

350 involved. A similar neuro-ethological approach has never been applied to quantify the extent of

351 the neural activation at the basis of the difference in yawn contagion latency as a function of the

352 emotional closeness.

353 The higher human sensitiveness to yawns emitted by friends and kin can be explained by the 354 peculiarity of the emotional attachment characterizing our species (Bowlby, 1969; Maestripieri, 355 2003). Compared to bonobos, the strong relationships established between humans are probably 356 qualitatively different, because they are built upon more complex and sophisticated emotional 357 foundations linked to cognition, memory, and memories. This interpretation is in line with 358 findings endorsing that affective and cognitive empathy cooperate in modulating the phenomenon 359 of yawn contagion in humans as it occurs for other kinds of unconsciously mimicked behaviours 360 (van Baaren et al., 2009). The idea that also the cognitive component of human empathy explains 361 some features of yawn contagion is supported by the ontogenetic co-emergence of yawn 362 contagion and theory of mind capacities in children (Anderson \& Meno, 2003; Helt et al., 2010; 363 Millen \& Anderson, 2011) and the correlation of these two phenomena in adults (Platek et al., 364 2003). Therefore, it seems that in humans affective empathy is enhanced by the cognitive 365 components concurring in awakening and nourishing the affective involvement characterizing 366 strong relationships (van Baaren et al., 2009).

367 The most intriguing and original result emerging from our cross-species analysis is the strong 368 similarity between human and bonobo contagion susceptibility when the stimulus comes from a 369 familiar, but weakly bonded subject. This finding indicates that the foundations of the empathic 370 mechanism are alike in the two species. The absence of a strong emotional involvement seems to 371 bring to light the most basic component of yawn contagion by removing the influence of the 372 higher and more complex layers characterizing the cognitive sphere of human empathy (e.g. 373 perspective taking, mental state attribution, theory of mind). As a whole, our cross-species 
374 approach supports the shared and multilayered architecture of animal empathy (Preston \& de

375 Waal, 2002; de Waal, 2008). Therefore, we cannot state that emotional contagion is always

376 highest in humans, but only that they are able to create a unique and extremely intense form of

377 emotional attachment, thanks to the complexity of the neural circuits linking social experiences

378 and cognitive capacities. When such a pervasive attachment is missing, humans climb down from

379 the highest step of the empathic podium to return to the understory layer which our species shares

380 with other great apes.

381

382 ACKNOWLEDGMENTS

383 Thank are due to Frank Rietkerk (Apenheul Primate Park, Apeldoorn, The Netherlands) and 384 Marianne Holtkötter (Wilhelma Zoo, Stuttgart, Germany) and the bonobo keepers for allowing 385 and facilitating this work. We also thank Francesca Coppola and White Palagio for their 386 important clarifying input in discussing results. 


\section{REFERENCES}

388 Altmann J. 1974. Observational study of behavior: sampling methods. Behaviour 49, 227-267.

389 Anderson JR, Meno P. 2003. Psychological influences on yawning in children. Current 390 psychology letters - Behaviour, brain \& cognition 11, http://cpl.revues.org/document390.html.

391 Anderson JR, Myowa-Yamakoshi M, Matsuzawa T. 2004. Contagious yawning in chimpanzees. 392 Proceedings of the Royal Society B 271, S468-S470. DOI 10.1098/rsbl.2004.0224.

393 Aureli F, Schaffner CM, Boesch C, Bearder SK, Call J, Chapman CA, et al. 2008. Fission-fusion 394 dynamics. Current Anthropology 49, 627-654. DOI 10.1086/586708.

395 Avenanti A, Sirigu A, Aglioti SM. 2010. Racial bias reduces empathic sensorimotor resonance 396 with other-race pain. Current Biology. DOI 10.1016/j.cub.2010.03.071.

397 Baenninger R. 1987. Some comparative aspects of yawning in Betta splendens, Homo sapiens, 398 Panthera leo, and Papio sphinx. Journal of Comparative Psychology 101, 349-354. DOI 399

400 401 10.1037/0735-7036.101.4.349.

Baenninger R. 1997. On yawning and its functions. Psychonomic Bulletin \& Review 4, 198-207.

$$
\text { DOI 10.3758/BF03209394. }
$$

Bartholomew AJ, Cirulli ET. 2014. Individual variation in contagious yawning susceptibility is highly stable and largely unexplained by empathy or other known factors. PLoS ONE $\mathbf{9}$,

405 Bourgeois P, Hess U. 2008. The impact of social context on mimicry. Biological Psychology 77, $406 \quad 343-352$. DOI 10.1016/j.biopsycho.2007.11.008.

407 Bowlby J. 1969. Attachment and loss. Volume 1 Attachment. Second Edition. New York, USA: 408 Basic Books.

409 Campbell MW, de Waal FBM. 2014. Chimpanzees empathize with group mates and humans, but 410 not with baboons or unfamiliar chimpanzees. Proceedings of the Royal Society B, 281, 411 20140013. DOI 10.1098/rspb.2014.0013. 
412 Campbell MW, de Waal FBM. 2011. Ingroup-outgroup bias in contagious yawning by 413 chimpanzees supports link to empathy. PLoS ONE 6, e18283. DOI 414 10.1371/journal.pone.0018283.

415 Chiao JY, Iidaka T, Gordon HL, Nogawa J, Bar M, Aminoff E. et al. 2008. Cultural specificity in 416 amygdala response to fear faces. Journal of Cognitive Neuroscience 20, 2167-2174. DOI $417 \quad$ 10.1162/jocn.2008.20151.

418 Cooper NR, Puzzo I, Pawley AD, Bowes-Mulligan RA, Kirkpatrick EV, Antoniou PA, Kennett S. 419 2012. Bridging a yawning chasm: EEG investigations into the debate concerning the role of 420 the human mirror neuron system in contagious yawning. Cognitive, Affective, \& Behavioral $421 \quad$ Neuroscience 12, 393-405. DOI 10.3758/s13415-011-0081-7.

422 Couzin I. 2007. Collective minds. Nature 445, 715-715. DOI 10.1038/445715a.

423 Cox CL, Uddin LQ, Di Martino A, Castellanos FX, Milham MP, Kelly C. 2011. The balance 424 between feeling and knowing: affective and cognitive empathy are reflected in the brain's 425 intrinsic functional dynamics. Social Cognition and Affective Neuroscience. DOI $426 \quad 10.1093 / \mathrm{scan} / \mathrm{nsr} 051$.

427 Davila-Ross M, Menzler S, Zimmermann E. 2008. Rapid facial mimicry in orangutan play. 428 Biology Letters 4, 27-30.

429 de Waal FBM, Ferrari PF. 2010. Towards a bottom-up perspective on human and animal 430 cognition. Trends in Cognitive Sciences 14, 201-207. DOI 10.1016/j.tics.2010.03.003.

431 de Waal FBM, Lanting F. 1997. Bonobo. The forgotten ape. Berkeley, CA, USA: University of 432 California Press.

433 de Waal FBM. 2008. Putting the altruism back into altruism: the evolution of empathy. Annual 434 Review of Psychology 59, 279-300. DOI 10.1146/annurev.psych.59.103006.093625.

435 de Waal FBM. 2012a. Empathy in primates and other mammals. In: Decety J, ed. Empathy: from 436 bench to bedside. Cambridge, Massachusetts: MIT press, 87-106. 
437 de Waal FBM. 2012b. A bottom-up view of empathy. In: de Waal FBM, Ferrari PF, eds. The

438 primate mind. Cambridge, Massachusetts: Harvard University Press, 121-138.

439 de Waal FBM. 2012c. The antiquity of empathy. Science 336, 874-876. DOI $440 \quad 10.1126 /$ science. 1220999.

441 Decety J. 2010. The neurodevelopment of empathy in humans. Developmental Neuroscience 32, 442 257-267. DOI 10.1159/000317771.

443 Decety J, Cowell JM. 2014. The complex relation between morality and empathy. Trends in $444 \quad$ Cognitive Sciences 18, 337-339. DOI 10.1016/j.tics.2014.04.008.

445 Decety J, Jackson PL. 2004. The functional architecture of human empathy. Behavioral and 446 Cognitive Neuroscience Reviews 3, 71-100. DOI 10.1159/000317771.

447 Demuru E, Palagi E. 2012. In bonobos yawn contagion is higher among kin and friends. PLoS $448 \quad$ ONE 7, e49613. DOI 10.1371/journal.pone.0049613.

449 Deputte BL. 1994. Ethological study of yawning in primates. I. Quantitative analysis and study of 450 causation in two species of Old World monkeys (Cercocebus albigena and Macaca 451 fascicularis). Ethology 98, 221-245. DOI 10.1111/j.1439-0310.1994.tb01073.x.

452 Dziobek I, Rogers K, Fleck S, Bahnemann M, Heekeren HR, Wolf OT, Convit A. 2008. 453 Dissociation of cognitive and emotional empathy in adults with Asperger syndrome using the 454 multifaceted empathy test (MET). Journal of Autism Develpmental Disorders 38, 464-473.

455 di Pellegrino G, Fadiga L, Fogassi L, Gallese V, Rizzolatti G. 1992. Understanding motor events: 456 a neurophysiological study. Experimental Brain Research 91, 176-180. DOI $457 \quad 10.1007 / \mathrm{BF} 00230027$.

458 Englander EK. 2007. Understanding violence. New Jersey, USA: Lawrence Erlbaum Associates 459 Inc. Publishers. 
460 Ferrari PF, Bonini L, Fogassi L. 2009. From monkey mirror neurons to primate behaviors:

461 possible "direct" and "indirect" pathways. Philosophical Transactions of the Royal Society B

$462 \quad 364,2311-2323$. DOI 10.1098/rstb.2009.0062.

463 Ferrari PF, Gallese V, Rizzolatti G, Fogassi L. 2003. Mirror neurons responding to the 464 observation of ingestive and communicative mouth actions in the monkey ventral premotor 465 cortex. European Journal of Neuroscience 17, 1703-1714. DOI 10.1046/j.1460$4669568.2003 .02601 . x$.

467 Fleagle JG. 2013. Primate adaptation and evolution. Third Edition. San Diego, California, USA: 468 Academic Press.

469 Furuichi T. 2011. Female contributions to the peaceful nature of bonobo society. Evolutionary $470 \quad$ Anthropology 20, 131-142. DOI 10.1002/evan.20308.

471 Gallese V, Fadiga L, Fogassi L, Rizzolatti G. 1996. Action recognition in the premotor cortex. 472 Brain 119, 593-609. DOI 10.1093/brain/119.2.593.

473 Guggisberg AG, Mathis J, Schnider A, Hess CW. 2010. Why do we yawn? Neuroscience \& 474 Biobehavioral Reviews 34, 1267-1276. DOI 10.1016/j.neubiorev.2010.03.008.

475 Haker H, Kawohl W, Herwig U, Rössler W. 2013. Mirror neuron activity during contagious 476 yawning-an fMRI study. Brain Imaging and Behavior 7, 28-34. DOI 10.1007/s11682-012$477 \quad 9189-9$.

478 Hammock EA, Young LJ. 2005. Microsatellite instability generates diversity in brain and socio479 behavioral traits. Science 308, 1630-1634. DOI 10.1126/science.1111427.

480 Hare B, Melis AP, Woods V, Hastings S, Wrangham R. 2007. Tolerance allows bonobos to 481 outperform chimpanzees on a cooperative task. Current Biology 17, 619-623. DOI $482 \quad$ 10.1016/j.cub.2007.02.040. 
483 Hare B, Wobber V, Wrangham R. 2012. The self-domestication hypothesis: evolution of bonobo 484 psychology is due to selection against aggression. Animal Behaviour 83, 573-585. DOI $485 \quad$ 10.1016/j.anbehav.2011.12.007.

486 Hatfield E, Rapson RL, Le Y-CL. 2009. Emotional contagion and empathy. In: Decety J, Ickes W, 487 eds. The social neuroscience of empathy. Cambridge, Massachusetts: MIT press, 19-30.

488 Hecht EE, Gutman DA, Preuss TM, Sanchez MM, Parr LA, Rilling JK. 2012. Process versus 489 product in social learning: comparative diffusion tensor imaging of neural systems for action 490 execution-observation matching in macaques, chimpanzees, and humans. Cerebral Cortex 23, 491 1014-1024. DOI 10.1093/cercor/bhs097.

492 Helt MS, Eigsti IM, Snyder PJ, Fein DA. 2010. Contagious yawning in autistic and typical 493 development. Child Development 81, 1620-1631. DOI 10.1111/j.1467-8624.2010.01495.x.

494 Kano T. 1992. The last ape: pygmy chimpanzee behavior and ecology. Stanford University Press. 495 Lawrence EJ, Shaw P, Baker D, Baron-Cohen S, David AS. 2004. Measuring empathy: reliability 496 and validity of the Empathy Quotient. Psychological Medicine 34, 911-919. DOI $497 \quad 10.1017 / \mathrm{S} 0033291703001624$.

498 Lehmann HE. 1979. Yawning: a homeostatic reflex and its psychological significance. Bulletin of 499 the Menninger Clinic 43, 123-136.

500 Maestripieri D. 2003. Attachment. In Maestripieri D, ed. Primate psychology. Cambridge, 501 Massachusetts, USA: Harvard University Press, 108-143.

502 Mancini G, Ferrari PF, Palagi E. 2013a. Rapid facial mimicry in geladas. Scientific Reports 3, $503 \quad 1527$ DOI $10.1038 /$ srep01527.

504 Mancini G, Ferrari PF, Palagi E. 2013b. In play we trust. Rapid facial mimicry predicts the 505 duration of playful interactions in geladas. PLoS ONE 8, e66481. DOI $506 \quad$ 10.1371/journal.pone.0066481. 
507 Marshall WL, Hamilton K, Fernandez Y. 2001. Empathy deficits and cognitive distortions in 508 child molesters. Sex Abuse 13, 123-130.

509 Massen JJ, Vermunt DA, Sterck EH. 2012. Male yawning is more contagious than female 510 yawning among chimpanzees (Pan troglodytes). PloS ONE 7, e40697. DOI $511 \quad$ 10.1371/journal.pone.0040697.

512 Masserman J, Wechkin MS, Terris W. 1964. Altruistic behavior in rhesus monkeys. American 513 Journal of Psychiatry 121, 584-585.

514 Millen A, Anderson JR. 2011. Neither infants nor toddlers catch yawns from their mothers. 515 Biology Letters 7, 440-442. DOI 10.1098/rsbl.2010.0966.

516 Minagawa-Kawai Y, Matsuoka S, Dan I, Naoi N, Nakamura K. et al. 2009. Prefrontal activation 517 associated with social attachment: Facial-emotion recognition in mothers and infants. $518 \quad$ Cerebral Cortex 19, 284-292. DOI 10.1093/cercor/bhn081.

519 Norscia I, Palagi E. 2011. Yawn contagion and empathy in Homo sapiens. PLoS ONE 6, e28472. 520 DOI 10.1371/journal.pone.0028472.

521 Palagi E, Norscia I. 2013. Bonobos protect and console friends and kin. PloS ONE 8, e79290. 522 DOI 10.1371/journal.pone.0079290.

523 Palagi E, Leone A, Mancini G, Ferrari PF. 2009. Contagious yawning in gelada baboons as a 524 possible expression of empathy. Proceedings of the National Academy of Sciences USA 106, 525 19262-19267. DOI 10.1073/pnas.0910891106.

526 Panksepp J, Panksepp JB. 2013. Toward a cross-species understanding of empathy. Trends in 527 Neurosciences 36, 489-496. DOI 10.1016/j.tins.2013.04.009.

528 Paukner A, Suomi SJ, Visalberghi E, Ferrari PF. 2009. Capuchin monkeys display affiliation 529 toward humans who imitate them. Science 325, 880-883. DOI 10.1126/science.1176269. 
530 Pfeifer JH, Iacoboni M, Mazziotta JC, Dapretto M. 2008. Mirroring others' emotions relates to

531 empathy and interpersonal competence in children. Neuroimage 39, 2076-2085. DOI $532 \quad$ 10.1016/j.neuroimage.2007.10.032.

533 Phillips C. 2009. The welfare of animals. The silent majority. The Netherlands: Springer.

534 Platek SM, Critton SR, Myers TE, Gallup GGJr. 2003. Contagious yawning: the role of self535 awareness and mental state attribution. Cognitive Brain Research 17, 223-227. DOI $536 \quad 10.1016 / \mathrm{S} 0926-6410(03) 00109-5$.

537 Preston SD, de Waal FBM. 2002. Empathy: Its ultimate and proximate bases. Behavioral and $538 \quad$ Brain Sciences 25, 1-20. DOI 10.1017/S0140525X02000018.

539 Provine RR. 1986. Yawning as a stereotyped action pattern and releasing stimulus. Ethology 72 , 540 109-122. DOI 10.1111/j.1439-0310.1986.tb00611.x.

541 Provine RR. 2005. Yawning. American Scientist 93, 532-539. DOI 10.1511/2005.6.532.

542 Provine RR. 2012. Curious behavior: yawning, laughing, hiccupping, and beyond. Cambridge 543 (MA), USA: The Belknap Press.

544 Rilling JK, Scholz J, Preuss TM, Glasser MF, Errangi BK, Behrens TE. 2012. Differences

545 between chimpanzees and bonobos in neural systems supporting social cognition. Social $546 \quad$ Cognitive \& Affective Neuroscience 7, 369-379. DOI 10.1093/scan/nsr017.

547 Ritter K, Dziobek I, Preißler S, Rüter A, Vater A, Fydrich T, Lammers C, Heekeren HR, Roepke 548 S. 2011. Lack of empathy in patients with narcissistic personality disorder. Psychiatry Research 549 187, 241-247.

550 Rizzolatti G, Craighero L. 2004. The mirror neuron system. Annual Review of Neuroscience 27, 551 169-192. DOI 10.1146/annurev.neuro.27.070203.144230.

552 Romero T, Konno A, Hasegawa T. 2013. Familiarity bias and physiological responses in 553 contagious yawning by dogs support link to empathy. PloS ONE 8, e71365. DOI 554 10.1371/journal.pone.0071365. 
555 Ross MD, Menzler S, Zimmermann E. 2008. Rapid facial mimicry in orangutan play. Biology

$556 \quad$ Letters 4, 27-30. DOI 10.1098/rsbl.2007.0535.

557 Singer T, Seymour B, O’Doherty JP, Stephan KE, Dolan RJ, Frith CD. 2006. Empathic neural 558 responses are modulated by the perceived fairness of others. Nature 439, 466-469. DOI $559 \quad 10.1038 /$ nature04271.

560 Špinka M. 2012. Social dimension of emotions and its implication for animal welfare. Applied 561 Animal Behaviour Science 138, 170-181. DOI 10.1016/j.applanim.2012.02.005.

562 Tan J, Hare B. 2013. Bonobos share with strangers. PloS ONE 8, e51922. DOI $563 \quad$ 10.1371/journal.pone.0051922.

564 Usui S, Senju A, Kikuchi Y, Akechi H, Tojo Y, Osanai H, Hasegawa T. 2013. Presence of 565 contagious yawning in children with autism spectrum disorder. Autism Research Treatment, 566971686. DOI $10.1155 / 2013 / 971686$.

567 Van Baaren R, Janssen L, Chartrand TL, Dijksterhuis A. 2009. Where is the love? The social 568 aspects of mimicry. Philosophical Transactions of the Royal Society B 364, 2381-2389. DOI $569 \quad 10.1098 /$ rstb.2009.0057.

570 Xu X, Zuo X, Wang X, Han S. 2009. Do you feel my pain? Racial group membership modulates 571 empathic neural responses. Journal of Neuroscience 29, 8525-8529. DOI $572 \quad$ 10.1523/JNEUROSCI.2418-09.2009.

573 Woodworth M, Porter S. 2002. In cold blood: characteristics of criminal homicides as a function 574 of psychopathy. Journal of Abnormal Psychology 111, 436-445.

575

576

577 Figure 1 - Timing distribution of yawn contagion in the two species. The error bars show the 578 mean $( \pm \mathrm{SE})$ of the individual frequency as a function of the 3-min time window. 
579 Figure 2 - Error bars showing the dyadic frequency of yawn contagion (number of responses per

580 yawn stimulus perceived) (mean $\pm \mathrm{SE}$ ) in the two species as a function of the relationships quality

581 linking the subjects involved.

582 Figure 3 - Error bars (mean $\pm \mathrm{SE}$ ) showing the timing distribution of the dyadic yawn contagion

583 in bonobos (a) and humans (b) as a function of the relationship quality shared by the subjects

584 involved.

585

586 Supplementary Video 1 - Video showing a yawn contagion event between two bonobo females

587 hosted at the Apenheul Primate Park (Apeldoorn, The Netherlands). The two females are laying

588 in proximity and are concurrently nursing their newborns. The female on the right, Zuani, yawns

589 at second 2. The female on the left, Kumbuka, perceives Zuani's yawn and emits a yawn response

590 at second 11. 


\section{Figure 1}

Timingdistribution of yawn contagion inthe two species.

Timing distribution of yawn contagion in the two species. The error bars show the mean $( \pm S E)$ of the individual frequency as a function of the 3-min time window. 


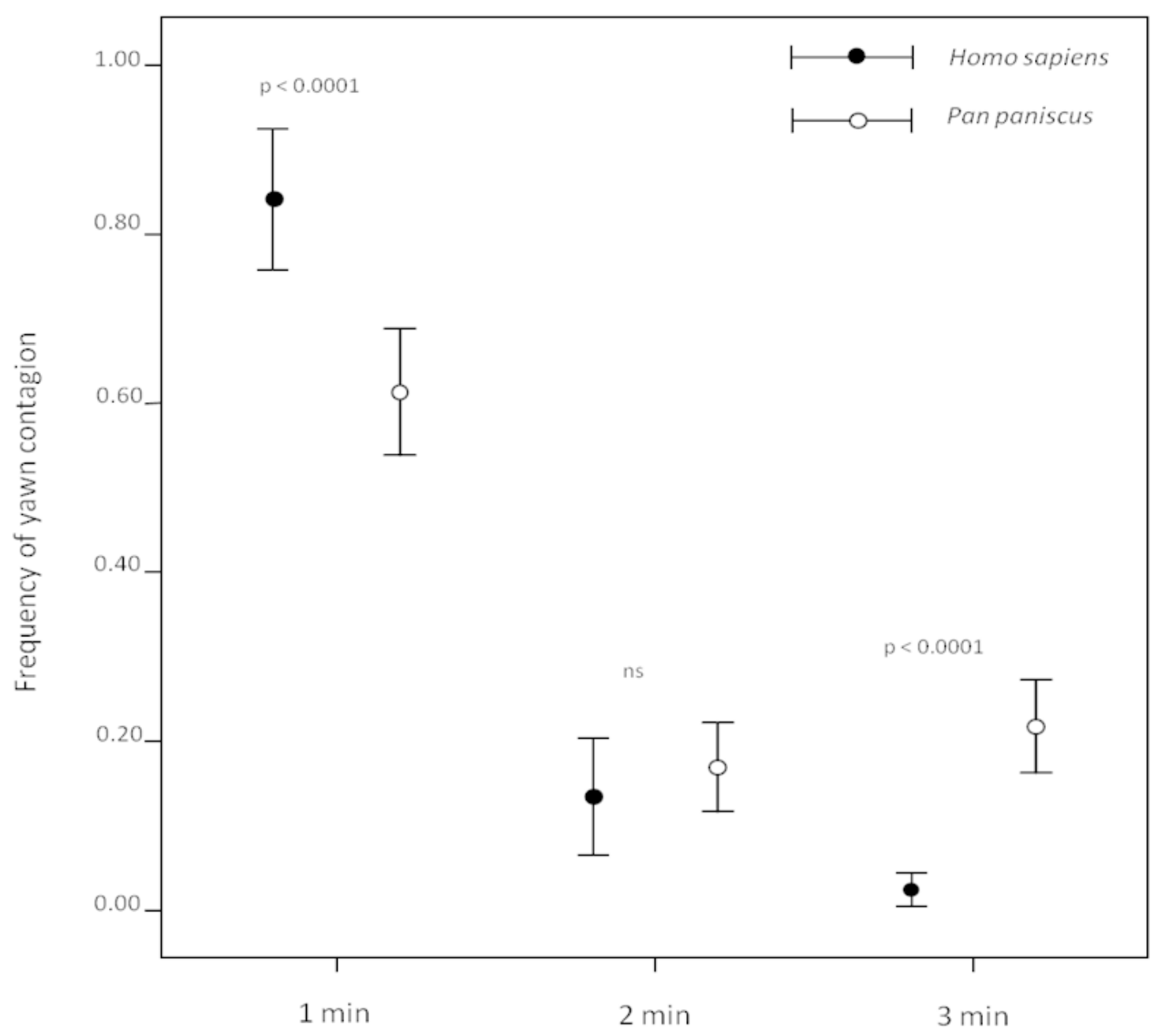

PeerJ reviewing PDF | (v2014:06:2275:1:0:NEW 11 Jul 2014) 


\section{Figure 2}

Yawn contagion and relationship quality in the two species.

Error bars showing the dyadic frequency of yawn contagion (number of responses per yawn stimulus perceived) (mean $\pm S E$ ) in the two species as a function of the relationships quality linking the subjects involved. 


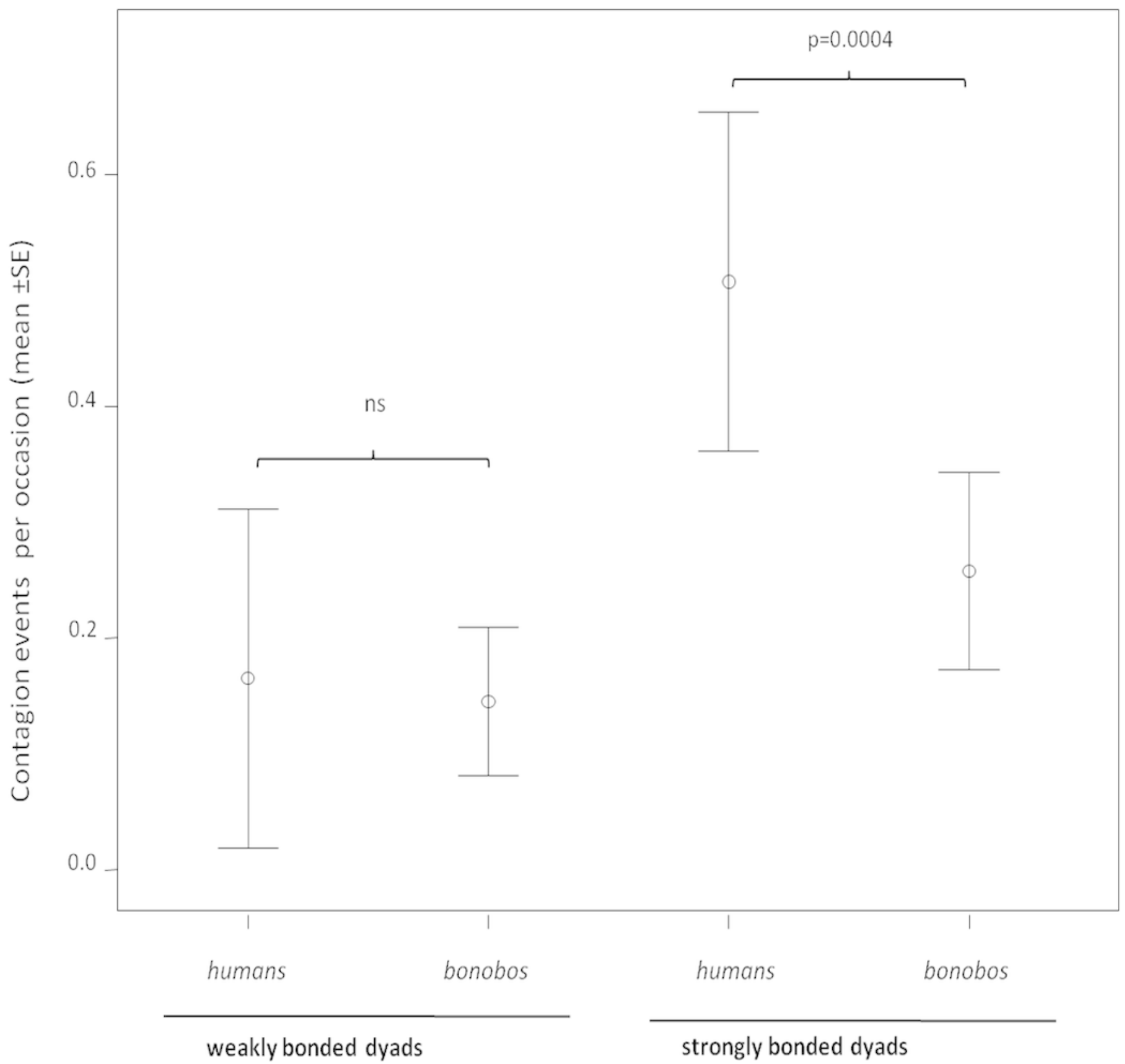




\section{Figure 3}

Latency of yawn contagion as a function of relationship quality.

Error bars (mean $\pm \mathrm{SE}$ ) showing the timing distribution of the dyadic yawn contagion in bonobos (a) and humans (b) as a function of the relationship quality shared by the subjects involved.
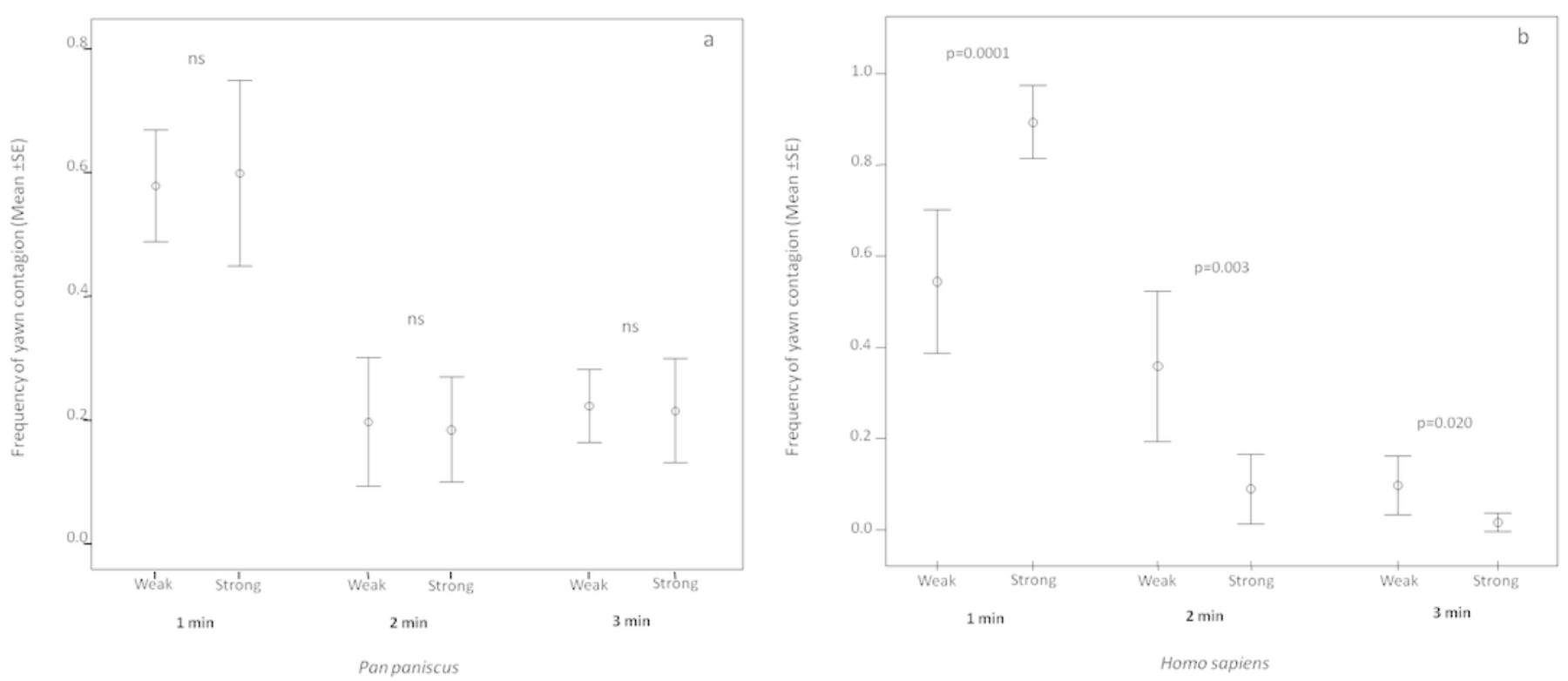


\section{Table 1 (on next page)}

LMM results.

을 $\quad$ Best LMM explaining the occurrence of yawn contagion ( AICc =-3.312). 
Table 1. Best LMM explaining the occurrence of yawn contagion (AICc =-3.312).

$\begin{array}{lllll} & \text { Numerator df } & \text { Denominator df } & \text { F } & \text { Significance level } \\ \text { Intercept } & 1 & 17.771 & 52.037 & 0.000\end{array}$

\section{FIXED FACTORS}

Social bonding**

1

72.536

$10.610 \quad 0.002$

Species*

1

17.380

$7.621 \quad 0.013$

RANDOM FACTORS

Variance

SE

Trigger's identity

0.0333

0.017

Observer's identity

0.0038

0.004

df: degrees of freedom; SE: standard error 